\title{
Type 1 fimbriae mutants of Escherichia coli K12: characterization of recognized afimbriate strains and construction of new fim deletion mutants
}

\author{
I. C. Blomfield, M. S. McClain and B. I. Eisenstein* \\ Department of Microbiology and Immunology, University \\ of Michigan Medical School, 6643 Medical Sciences \\ Building II, Ann Arbor, Michigan 48109, USA.
}

\section{Summary}

We have used Southern hybridization analysis to characterize the extent of fim homology in recognized type 1 fimbriae mutants of Escherichia coli K12, including strains HB101, P678-54, and VL584. We have found extensive homology in strain HB101, and confirm that P678-54 lacks the majority of fim DNA. Strain VL584 contains a deletion of the entire fim region. We have used a new allelic exchange procedure to generate novel fim deletion derivatives of strains MG1655, MM294, and YMC9. To increase the utility of the new deletion strains we also isolated recA derivatives of each mutant. These strains facilitate the isolation, characterization, and manipulation of cloned fimbriae genes from diverse sources.

\section{Introduction}

The construction of mutants is an essential element in the genetic analysis of microbial phenotypes and in the manipulation of cloned genes. The mutants that contain a deletion of the entire region of interest, being those that are least capable of reverting to wild type, are often the most useful for cloned-gene manipulation and genetic analysis. Thus, strains of Escherichia coli are often selected as cloning hosts, in part by virtue of the fact that they contain chromosomal deletions in the genes that are to be cloned and expressed.

We are particularly interested in the genetic regulation in E. coli of type 1 fimbriae, which are peritrichously arranged organelles that are important in bacterial adherence and colonization. The purpose of this communication is twofold: first, we describe the Southern hybridization and partial genetic analysis of three known Fim ${ }^{-}$mutants of $E$. coli K12, i.e. HB101 (Boyer and Roulland-Dussoix, 1969), P678-54 (Alder et al., 1967), and VL584 (Freitag et al.,

Received 1 November, 1990; revised 7 February, 1991. "For correspondence. Tel. (313) 764 1466; Fax (313) 7643562.
1985). Strain HB101, lacking the HsdR restriction enzyme and being phenotypically afimbriate, has been used widely in the cloning and subsequent study of type 1 (Clegg, 1982; Purcell and Clegg, 1983; Orndorff and Falkow, 1984; Clegg et al., 1985; Klemm et al., 1985; Orndorff et al., 1985; Klemm, 1986) and other classes of fimbriae (Marrs et al., 1985; Morrissey and Dougan, 1986; Ott et al., 1986; Pawelzik et al., 1988). However, this strain also lacks the HsdM methylase, and consequently transfer of plasmid DNA from HB101 to $h s d R^{+}$strains is inefficient. Moreover, HB101 appears to carry chromosomal markers capable of complementing defects in some of the cloned fimbriae genes (Pallesen et al., 1989). Here we show that HB101 contains considerable homology to the type 1 fimbriae genes. We also confirm that P678-54, another strain employed in the analysis of fimbriae (Hull et al., 1981; Normark et al., 1983; Orndorff and Falkow, 1984; Orndorff et al., 1985), lacks the majority of fim sequences (Moseley et al., 1980). Nevertheless, both Southern hybridization analysis and genetic complementation studies suggest that P678-54 retains a copy of the important regulatory gene, fimB (Klemm, 1986). In addition, we report that strain VL584, constructed in this laboratory as a derivative of strain CSH50 (Miller, 1972), contains a deletion of all the known type 1 fimbriae genes.

The second purpose of this communication, in the light of our studies of the recognized afimbriate mutants, and in response to the need for fim-deleted, $h s d R^{-} h s d M^{+}$host strains in our and other laboratories, is the construction of new $\Delta$ fim, $\Delta$ recA mutants of the E. coli K12 strain MM294 (Meselson and Yuan, 1968) and its $\Delta /$ lac derivative, YMC9 (Backman et al., 1981). We have also constructed a deletion mutant of the wild-type strain MG1655 (Guyer et al., 1980). This mutant, because it has undergone comparatively little manipulation, and because it contains a defined deletion of the type 1 fimbriae genes, should provide an improved host for studies of plasmid-based fimbriae expression.

\section{Results}

Southern hybridization analysis of afimbriate strains

Chromosomal DNA isolated from strains P678-54 (kindly supplied by B. Bachmann as CGSC4928), HB101 (from 

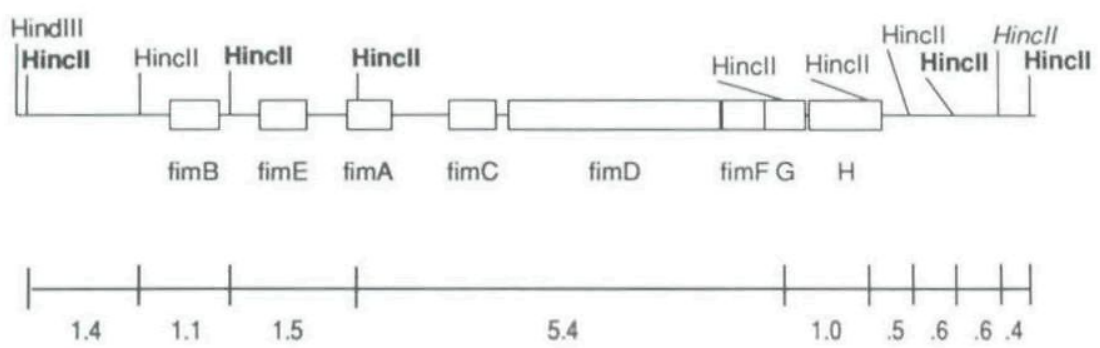

Hincll fragment sizes in $\mathrm{kb}$
Fig. 1. Genetic and physical organization of the fim region of $E$. coli $\mathrm{K} 12$. The positions of HindIII, Hpal, Hincll and Sall restriction endonuclease sites, together with the Hincll restriction fragment sizes, are shown. The subset of Hincll sites that are also cut by Hpal are emphasized in bold type. The unique Sall site is indicated by italics (Hincli). and is the second site from the right. The extent of probes $A$ and $B$ is also indicated. Probe DNA comprises gel-purified restriction endonuclease fragments derived from the cloned type 1 fimbriae genes of strain MG1655 and was' labelled using the multiprime kit supplied by Amersham.

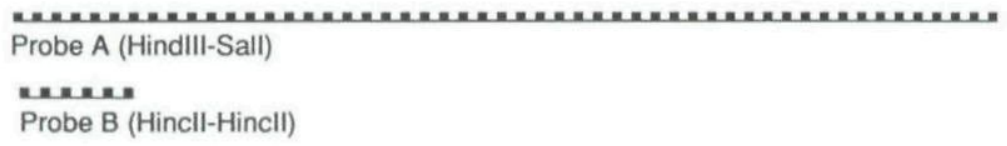

our own and P. Klemm's laboratory), VL584, and MG1655 (CGSC6300, wild-type fimbriate strain) were digested with either Hpal or Hincll and examined using Southern hybridization. The organization of the wild-type fim region, showing the positions of relevant restriction endonuclease sites, is shown in Fig. 1. The positions of most restriction endonuclease sites were originally determined by Klemm (Klemm et al., 1985) and recently confirmed and extended in our laboratory with independently cloned fimbriae genes (our unpublished data). Duplicate Southern blots were prepared, and each blot was hybridized to one of two fim DNA probes. Probe A, a $12 \mathrm{kbp}$ Hindlll-Sall fragment, encompasses the entire fim gene cluster, and probe $\mathrm{B}, \mathrm{a}$ $1.4 \mathrm{kbp}$ Hincll fragment, includes sequences upstream of fimB (Fig. 1).

An Hpal digest of chromosomal DNA isolated from MG1655 produces four bands of 7.3, 2.5, 1.5 and $0.9 \mathrm{kbp}$ that hybridize with probe A (Fig. 2, lane 4). Probe B hybridizes with the $2.5 \mathrm{kbp}$ fragment only; thus, this band encompasses the region upstream of, and including, the fimB gene (data not shown). Digestion of DNA isolated from P678-54 with $\mathrm{Hpal}$ produces a single $2.5 \mathrm{kbp}$ fragment that hybridizes to both probes, suggesting that this strain may contain the fimB gene (Fig. 2, lane 3). To investigate this hypothesis, we carried out additional hybridization studies with chromosomal DNA digested with Hincll. Hybridization of Hincll-digested MG1655 DNA to probe $A$ led to the detection of several fragments, including sequences of $1.4 \mathrm{kbp}$ and $1.1 \mathrm{kbp}$, that include the region upstream of, and including, $\operatorname{fim} B$, respectively (Figs 1 and 4). Hybridization of the Hincll-digested MG1655 DNA with probe B detected the $1.4 \mathrm{kbp}$ band only (Fig. 4), verifying the identity of this fragment. As predicted, fragments of $1.4 \mathrm{kbp}$ and $1.1 \mathrm{kbp}$ are also seen in strain P678-54 (data not shown). We have also determined, using a fimB-specific probe (data not shown), that the $1.1 \mathrm{kbp}$ Hincll fragment of strain P678-54 includes at least part of the fimB gene. These data confirm that P678-54 contains a deletion of most of the fim gene cluster (Moseley et al., 1980), but suggest that it may retain a copy of $\operatorname{fimB}$.

Hybridization of DNA isolated from our laboratory stock of HB101 to probe A shows that this strain contains

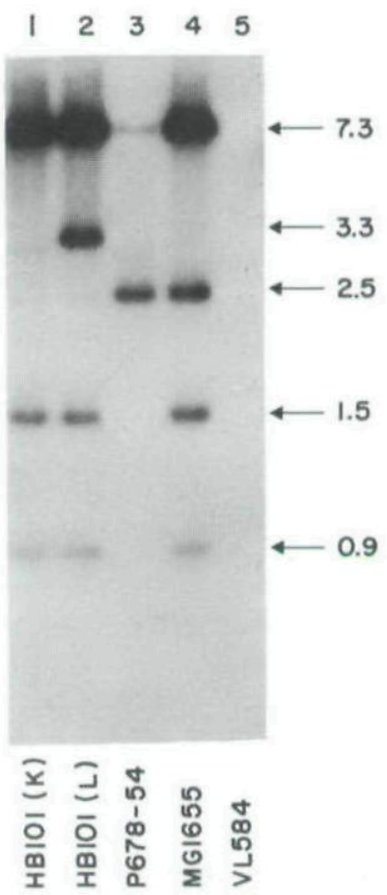

Fig. 2. Southern hybridization analysis of fim homology in afimbriate mutants, HB101, P678-54, and VL584, and fimbriate strain MG1655. Chromosomal DNA from different stocks of HB101, (K, Klemm; L, our own laboratory) was included in the study for comparison. DNA isolated from the indicated strain was digested with $\mathrm{Hpal}$, separated on a $1 \%$ agarose gel, and simultaneously blotted to nitrocellulose to produce duplicate filters. Hybridizations were carried out at high stringency (Maniatis et al., 1982) using (A) the entire fim region (probe A, Fig. 1), or (B) a $1.4 \mathrm{kbp}$ Hincll fragment (probe B, Fig. 1) (not shown). The sizes of restriction fragments are indicated in kbp. 
extensive fim homology (Fig. 2, lane 2). Digestion of the DNA with Hpal produces three bands of $7.3,1.5$, and $0.9 \mathrm{kbp}$ that co-migrate with the MG1655 sequences, and a fourth band of approximately $3.3 \mathrm{kbp}$ (Fig. 2). Since the larger $(3.3 \mathrm{kbp})$ fragment hybridizes with probe $\mathrm{B}$, we suggest that our laboratory stock of HB101 contains an insertion of approximately $0.8 \mathrm{kbp}$ in the fim $\mathrm{B}$ region (data not shown). Surprisingly, the second stock of HB101 contains a deletion in the fim $B$ region; we detected no signal when chromosomal DNA was hybridized to probe $B$ (data not shown). Finally, we were unable to detect any homology between the fim probes and chromosomal DNA isolated from strain VL584, showing that this strain contains a deletion of the entire fim region (Fig. 2, lane 5).

We have shown previously that the oscillating inversion of a $314 \mathrm{bp}$ chromosomal element controls fimbrial phase variation (Abraham et al., 1985). Klemm and colleagues have determined that $f i m B$ and fimE influence this inversion and have suggested that their products may in fact be site-specific DNA recombinases (Klemm, 1986; Pallesen et al., 1989). In line with the Klemm hypothesis, strains lacking both fimB and fimE should not support recombination of the invertible element. To investigate the genetic content of strains HB101, P678-54, and VL584 further, we tested whether the invertible element, carried on a plasmid, rearranged in the appropriate site-specific manner in each strain. Accordingly, each strain was transformed with a plasmid containing the fim invertible element, but lacking both fimB and fimE (our unpublished data), and the orientation of the invertible element was determined by restriction endonuclease digestion and Southern hybridization analysis (data not shown). We found that although strain P678-54 is capable of supporting inversion of a plasmid-borne fim invertible element, strains VL584 and HB101 (from our laboratory) were not.

\section{Construction of fim deletion strains by allelic exchange}

We have used allelic exchange and P1 transduction to generate afimbriate recA mutants of $E$. coli K12 strains MG1655, MM294, and YMC9. The $\Delta$ fim mutants were constructed using allelic exchange; recA mutants of each $\Delta$ fim derivative were then isolated using $\mathrm{P} 1$ transduction. The allelic exchange procedure, which is described in detail in the accompanying paper (Blomfield et al., 1991), employs a temperature-sensitive cloning vector (Hamilton et al., 1989). Used in conjunction with a specially constructed intermediate strain that contains a $\mathrm{SacB}-\mathrm{Neo}^{R}$ cassette (counterselectable and selectable markers, respectively) replacing part of the targeted chromosomal sequences, cloned DNA is exchanged for the corresponding chromosomal region in three steps. In the first step, plasmid integrate derivatives of the intermediate strain are selected at the non-permissive temperature for plasmid replication $\left(42^{\circ} \mathrm{C}\right)$. Following a period of growth at the elevated temperature (the second step), bacteria are plated onto sucrose agar. Since the expression of $s a c B$ is lethal in the presence of sucrose, this procedure permits selection of recombinant bacteria that have both excised and cured the chromosomal markers.

To construct the $\Delta$ fim mutants, we employed the sacB-containing relative of MG1655, strain AAEC064, or similar derivatives of strains MM294 or YMC9, in conjunction with the temperature-sensitive plasmid, pIB310. Plasmid pIB310 contains an extensive deletion of fim DNA, but retains sequences that flank the known fim genes. The plasmid contains $1.4 \mathrm{kbp}$ of DNA corresponding to the region situated upstream of $f_{i m} B$, extending from the HindIII site to an Eco0109 site, and $0.6 \mathrm{kbp}$ normally situated downstream of fim $\mathrm{H}$ extending from an $\mathrm{Hpal}$ site to the Sall site (Fig. 3).

The construction of the $\operatorname{sac} B$ derivative of strain MG1655, AAEC064, is described in the accompanying paper (Blomfield et al., 1991). In constructing similar derivatives of MM294 and YMC9, we transferred the sacB genes from AAEC064 using allelic exchange. Use of this approach, rather than $\mathrm{P} 1$ transduction, ensured that the intermediate derivatives did not acquire the closely linked wild-type $h s d R$ region from strain AAEC064. We moved the $\mathrm{SacB}-\mathrm{Neo}^{R}$ cassette situated on the temperature-sensitive plasmid pIB230 into the chromosome of MM294 and YMC9, essentially as described previously (Blomfield et al., 1991). Plasmid pIB230 was first constructed in vivo by exchange of the $\mathrm{sacB}-\mathrm{Neo}^{\mathrm{R}}$ cassette contained in strain AAEC064 for the wild-type fim sequences situated on plasmid pIB308.

We transferred the fim deletion from plasmid plB310 into the chromosomes of the intermediate strains using the protocol outlined above; Fig. 3 illustrates the expected allelic exchange. As predicted, the mutants were phenotypically afimbriate, failing to react with a type 1 fimbriaespecific monoclonal antibody (Eisenstein et al., 1983) or to agglutinate yeast cells (Duguid and Gillies, 1957). To confirm that each strain had acquired the correct chromosomal structure, one sucrose-resistant isolate of each intermediate strain was examined by Southern hybridization analysis (Fig. 4). Chromosomal DNA isolated from the original parent strains (MG1655, MM294, and YMC9), the intermediate derivatives (AAEC064, AAEC160, and AAEC162), and the corresponding $\triangle$ fim derivatives (AAEC072, AAEC173, and AAEC175) were digested with Hincll and blotted onto duplicate nitrocellulose filters following separation on a $1 \%$ agarose gel. Irrespective of which probe was used (probe A or B, Fig. 1), we detected an identical pattern of bands in each deletion mutant (Fig. 4). In each case, only a single prominent band of the expected $2.0 \mathrm{kbp}$ size was seen.

To increase the utility of the $\Delta$ fim mutants for later 

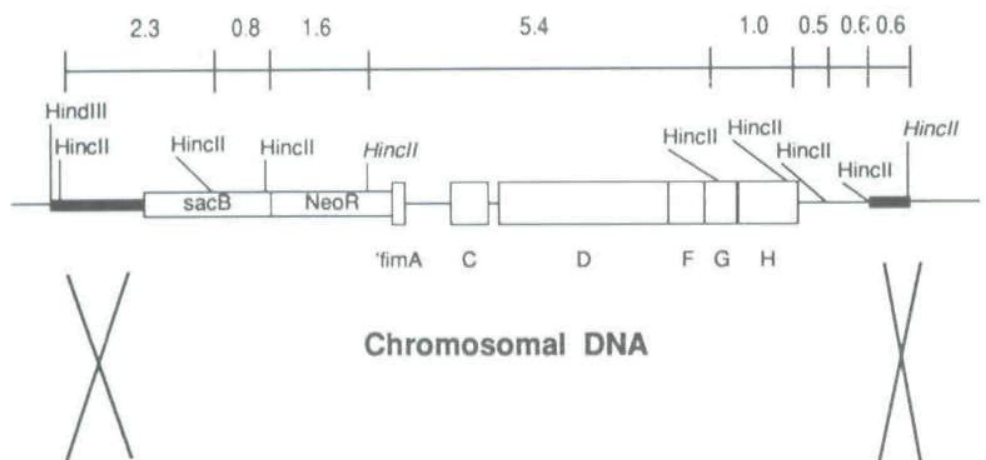

\section{Chromosomal DNA}

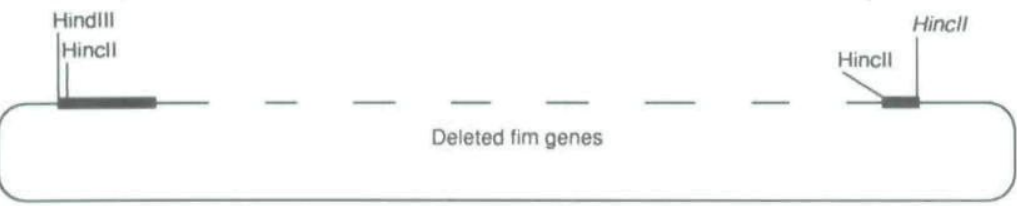

Plasmid DNA

Reciprocal recombination and plasmid curing
Fig. 3. Homologous recombination generates fim deletion mutants by allelic exchange. The physical and genetic organization of the intermediate strains (AAEC064, AAEC160, and AAEC162), showing the positions of HindIII. Hincll and Sall restriction endonuclease sites, together with the Hincll restriction fragment sizes, are shown. Homologous sequences (shaded) shared by the temperature-sensitive plasmid pIB310 and the intermediate strains are indicated. The subset of Hincll sites that are also cut by Sall are indicated by italics; these sites are within the chromosomal $\mathrm{Neo}^{R}$ gene and at the rightmost part of the chromosomal DNA shown (both before and after recombination) and of the plasmid DNA insert.
A

$\begin{array}{lllllllll}1 & 2 & 3 & 4 & 5 & 6 & 7 & 8 & 9\end{array}$
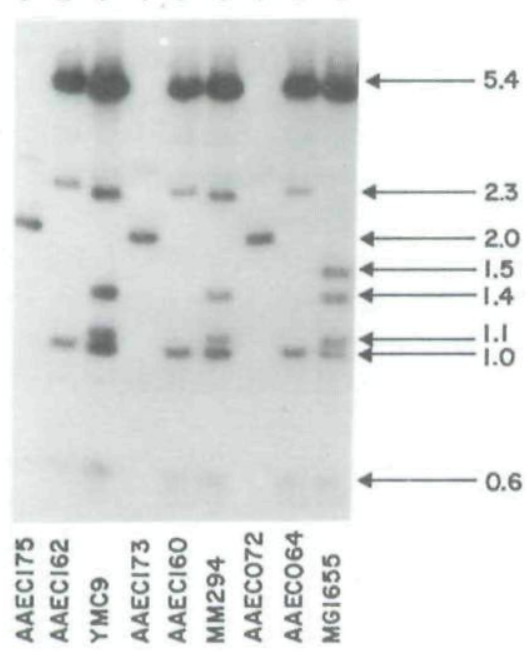

B
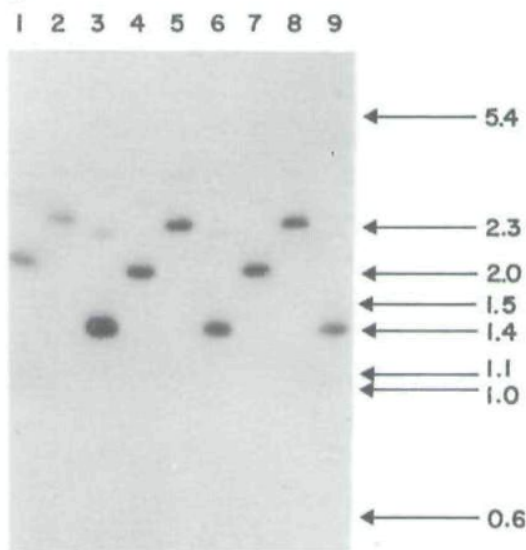

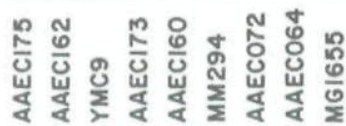

Fig. 4. Southern hybridization analysis of parent (MG1655, MM294, and YMC9), intermediate (AAEC064, AAEC160, and AAEC162) and fimdeletion (AAEC072, AAEC172, and AAEC175) strains. Chromosomal DNA isolated from the indicated strain was digested with Hincll, separated on a $1 \%$ agarose gel and simultaneously blotted to nitrocellulose to produce duplicate filters. Hybridizations were carried out at high stringency (Maniatis et al., 1982) using (A) the entire fim region (probe A, Fig. 1) or (B) a $1.4 \mathrm{kbp}$ Hincll fragment (probe B, Fig. 1). The sizes of restriction fragments are indicated in kbp. Note that strains MM294 and YMC9 lack the $1.5 \mathrm{kbp}$ fragment detected in MG1655 when probe $A$ is used. These strains contain a fragment of $2.3 \mathrm{kbp}$ instead, suggesting that they may contain an insertion of $0.8 \mathrm{kbp}$ in the fimE region. 
genetic studies, we next isolated recA derivatives of each strain. Bacteriophage P1, grown on strain JC10240 (Csonka and Clark, 1979), was used to transduce the recA deletion and the closely linked copy of $T n 10$ into each $\Delta$ fim mutant. Tetracycline-resistant transductants of AAEC072, AAEC173, and AAEC175, termed AAEC078, AAEC177, and $A A E C 179$, respectively, were screened for increased sensitivity to ultraviolet irradiation to confirm acquisition of the $r e c A$ deletion. Finally, we isolated tetracycline-sensitive derivatives of each strain by selecting mutants resistant to quinaldic acid (Bochner et al., 1980). Tetracycline-sensitive mutants of strains AAEC078, AAEC177, and AAEC179 were named AAEC191, AAEC185, and AAEC189, respectively.

\section{Discussion}

In this study we have found that two afimbriate $E$. coli strains, HB101 and P678-54, commonly used in the cloning and genetic analysis of fimbriae genes, contain segments of fim DNA. Samples of strain HB101 from our laboratory and from that of Klemm (Klemm et al., 1985) each contain considerable fim homology. Nevertheless, they differ in their hybridization patterns to the fim probes. In contrast, strain VL584 was found to contain an extensive deletion that includes, and goes beyond, the entire fim region. The hybridization analysis of strain P678-54, together with our genetic complementation data, suggest that the fim deletion in this strain extends from a point downstream of $\operatorname{fim} B$ to a position beyond the end of the fimH gene. Thus strain P678-54 seems to contain an active copy of fimB.

The simplest interpretation of our hybridization analysis of HB101 is that the two examined samples of this strain, although different, each contain lesions in the fimB region. Genetic complementation analysis of HB101 from our own laboratory suggests that this strain lacks both fimB and fimE; the strain is unable to support DNA inversion on a plasmid substrate. In sharp contrast, Klemm and colleagues have observed evidence of genetic complementation of the invertible element in their HB101 strain (Pallesen et al., 1989). Since fimE mutants are fimbriate (Orndorff and Falkow, 1984), and since neither sample of HB101 produces fimbriae when transformed with the cloned fim $B$ gene (data not shown), we suggest that both of these strains contain additional lesions. Given the contradictory complementation data described above, together with our finding of an active fimB in P678-54, we recommend that some prior observations concerning fim regulation should be repeated in a fim-deleted genetic background.

In view of the problems noted above, we felt compelled to construct new fim mutants that would serve as better hosts for future studies of fimbriae regulation. By intro- ducing a deletion into cloned fimbriae genes in vitro and then transferring the construction into the chromosome by allelic exchange, we have constructed a panel of $\Delta$ fim mutants that should serve a variety of needs. These strains have several useful characteristics, in addition to containing a defined and complete deletion of all the known type 1 fimbriae genes. Several constructs will be especially appropriate for cloning purposes, whereas another, discussed below, is as close to the $\mathrm{K} 12$ wild type as is practicable and will be particularly useful in studies of genetic regulation. Thus, for gene cloning, the $\Delta$ fim mutants of MM294 (strain AAEC185) and of its $\Delta / a C$ derivative, YMC9 (strain AAEC189), are rec $A^{-} e n d A^{-}$and lack the $h s d$ restriction endonuclease, but, unlike HB101, retain the hsd methylase. As such, they are efficiently transformed and produce excellent yields of plasmid DNA. Since plasmid DNA isolated from these strains is appropriately methylated, it efficiently transforms $h s d R^{+}$strains such as MG1655 (data not shown). Moreover, since these strains lack the HsdR restriction enzyme, they should provide useful hosts for cloning various fimbriae genes from many sources. Likewise, strain AAEC189, containing a deletion of the lac genes, will be useful for constructing and manipulating fim-lac fusions, as we have already found (data not shown).

The characteristics displayed by strains AAEC185 and AAEC189, although preferable in strains used to clone and manipulate DNA, are less important for plasmid-based studies of gene control. In such a situation it is preferable to employ a strain that resembles the wild type as closely as possible. To fulfil this requirement, we constructed a $\Delta$ fim derivative of our K12 wild-type strain MG1655, a strain that has undergone comparatively little manipulation. An additional benefit of using MG1655 is that, as the host for an extensive collection of drug resistance markers covering the entire chromosome (Singer et al., 1989), genetic manipulation of this strain (e.g. by P1 transduction) is comparatively easy. In view of these advantages, and the fact that the fim deletion in AAEC072 is so well defined, we consider this MG1655 derivative a more desirable host than VL584.

The novel and isogenic fim deletion mutants described in this communication should be useful in a variety of studies involving fimbriae regulation. For example, they should help to clarify the relationship between type 1 fimbriae, colony morphology, and Flu variation (Diderichsen, 1980). Variants of flu are distinguished by differences in colony morphology and auto-agglutination; $\mathrm{flu}^{-}$ bacteria, which auto-agglutinate during growth in liquid culture, form larger rougher colonies than $\mathrm{flu}^{+}$cells, which do not auto-agglutinate. Variation of the flu phenotype apparently correlates with the expression of type 1 fimbriae, in that $\mathrm{flu}^{+}$cells are fimbriate, whereas flu ${ }^{-}$cells are not. We are currently examining our $\Delta$ fim derivatives to 
assess which, if any, of the characteristics associated with flu variation are determined directly by the presence of type 1 fimbriae. In addition, we are using the $\triangle r e c A$ derivative of AAEC072 (strain AAEC078) to obtain further characterization of the roles of FimB and FimE in the fim-specific DNA inversion event. As expected, the new $\triangle$ fim strains do not support the site-specific DNA inversion when transformed with the invertible element alone (data not shown).

\section{Experimental procedures}

\section{Bacterial strains, plasmids and growth media}

All strains are derivatives of $E$. coli K12. HB101 was from our own or P. Klemm's laboratory. MG1655 (CGSC6300) and P678-54 (CGSC4928) were from B. Bachmann. VL584 was from our own laboratory stocks. Strains MM294 and YMC9 were purchased from ATCC. Plasmid plB310 was constructed from cloned fim DNA from MG1655 (our unpublished data) and a derivative of the temperature-sensitive vector, pMAK705 (Hamilton et al., 1989). The different regions of fim homology are separated by a $10 \mathrm{bp}$ BamHI linker (Pharmacia). Bacteria were cultured on LB media, supplemented with antibacterial agents as necessary (Maniatis et al., 1982) at $37^{\circ} \mathrm{C}$ unless otherwise stated. The fim deletion mutants were isolated on sucrose agar (LB agar with $6 \%$ sucrose, but lacking sodium chloride) at $30^{\circ} \mathrm{C}$.

\section{Recombinant DNA techniques}

All methods have been described by Maniatis et al. (1982). Restriction endonucleases and T4 ligase were obtained from BRL.

\section{Acknowledgements}

We thank B. Bachmann, P. Klemm, and S. Kushner for strains and plasmids, and P. Calie, D. Higgins, and J. Princ for helpful discussions and comments. This work is supported, in part, by Public Health Service Research Grant Al24734 and Training Grant 5T32 Al07360, each from the National Institutes of Health.

\section{References}

Abraham, J.M., Freitag, C.S., Clements, J.R., and Eisenstein, B.I. (1985) An invertible element of DNA controls phase variation of type 1 fimbriae of Escherichia coli. Proc Natl Acad Sci USA 82: 5724-5727.

Alder, H.I., Fisher, W.D., Cohen, A., and Hardigree, A. (1967) Miniature Escherichia coli cells deficient in DNA. Proc Natl Acad Sci USA 57: 321-326.

Backman, K., Chen, Y.-M., and Magasanik, B. (1981) Physical and genetic characterization of the $g \ln A-g \ln G$ region of the Escherichia coli chromosome. Proc Natl Acad Sci USA 78: 3743-3747.

Blomfield, I.B., Vaughn, V., Rest, R.F., and Eisenstein, B.I. (1991) Allelic exchange in Escherichia coli using the Bacillus subtilis $s a c B$ gene and a temperature sensitive pSC101 replicon. Mol Microbiol 5: 1447-1457.
Bochner, B., Huang, H.C., Schieven, G., and Ames, B.N. (1980) Positive selection for loss of tetracycline resistance. J Bacteriol 143: 926-933.

Boyer, H.W., and Roulland-Dussoix, D. (1969) A complementation analysis of the restriction and modification of DNA in Escherichia coli. J Mol Biol 41: 459-472.

Clegg, S. (1982) Cloning of genes determining the production of mannose-resistant fimbriae in a uropathogenic strain of Escherichia coli belonging to serogroup O6. Infect Immun 38: 739-744.

Clegg, S., Prucker, J., and Purcell, B.K. (1985) Complementation analyses of recombinant plasmids encoding type 1 fimbriae of members of the family Enterobacteriaceae. Infect Immun 50: 338-340.

Csonka, L.N., and Clark, A.J. (1979) Deletions generated by the transposon $\mathrm{Tn} 10$ in the $\mathrm{srl}$ recA region of the Escherichia coli K-12 chromosome. Genetics 93: 321-343.

Diderichsen, B. (1980) flu, a metastable gene controlling surface properties of Escherichia coli. J Bacteriol 141: 858-867.

Duguid, J.P., and Gillies, R.R. (1957) Fimbriae and adhesive properties in dysentery bacilli. J Pathol Bacteriol 74: 397-411.

Eisenstein, B.I., Clements, J.R., and Dodd, D.C. (1983) Isolation and characterization of a monoclonal antibody directed against type 1 fimbriae organelles from Escherichia coli. Infect Immun 42: 333-340.

Freitag, C.S., Abraham, J.M., Clements, J.R., and Eisenstein, B.I. (1985) Genetic analysis of the phase variation control of expression of type 1 fimbriae in Escherichia coli. $J$ Bacteriol 162: 668-675.

Guyer, M.S., Reed, R.R., Steitz, J.A., and Low, K.B. (1980) Identification of a sex-factor-affinity site in $E$. coli as $\gamma \delta$. Cold Spring Harbor Symp Quant Biol 45: 135-140.

Hamilton, C.M., Aldea, M., Washburn, B.K., Babitzke, P., and Kushner, S.R. (1989) New method for generating deletions and gene replacements in Escherichia coli. J Bacteriol 171: 46174622.

Hull, R.A., Gill, R.E., Hsu, P., Minshew, B.H., and Falkow, S. (1981) Construction and expression of recombinant plasmids encoding type 1 or D-mannose-resistant pili from a urinary tract infection Escherichia coli isolate. Infect Immun 33: 933-938.

Klemm, P. (1986) Two regulatory fim genes, fimB and fimE, control the phase variation of type 1 fimbriae in Escherichia coli. EMBO J 5: 1389-1393.

Klemm, P., Jorgensen, B.J., van Die, I., de Ree, H., and Bergmans, H. (1985) The fim genes responsible for synthesis of type 1 fimbriae in Escherichia coli, cloning and genetic organization. Mol Gen Genet 199: 410-414.

Maniatis, T., Fritsch, E.F., and Sambrook, J. (1982) Molecular Cloning. A Laboratory Manual. Cold Spring Harbor, New York: Cold Spring Harbor Laboratory Press.

Marrs, C.V., Schoolnik, G., Koomey, J.M., Hardy, J., Rothbard, J., and Falkow, S. (1985) Cloning and sequencing of a Moraxella bovis pilin gene. J Bacteriol 163: 132-139.

Meselson, M., and Yuan, R. (1968) DNA restriction enzyme from E. coli. Nature 217: 1110-1114.

Miller, J.H. (1972) Experiments in Molecular Genetics. Cold Spring Harbor, New York: Cold Spring Harbor Laboratory Press.

Morrissey, P.M., and Dougan, G. (1986) Expression of a cloned 987P adhesion-antigen fimbrial determinant in Escherichia coli K-12 HB101. Gene 43: 79-84.

Moseley, S.L., Huq, I., Alim, A.R.M.A., So, M., Samed PourMotalebi, M., and Falkow, S. (1980) Detection of enterotoxigenic Escherichia coli by DNA colony hybridization. J Inf Dis 142: 892-898. 
Normark, S., Lark, D., Hull, R., Norgren, M., Baga, M., O'Hanley, P., Schoolnik, G., and Falkow, S. (1983) Genetics of digalactoside-binding adhesin from a uropathogenic Escherichia coli strain. Infect Immun 41: 942-949.

Orndorff, P.E., and Falkow, S. (1984) Identification and characterization of a gene product that regulates type 1 piliation in Escherichia coli. J Bacteriol 160: 61-66.

Ott, M., Hacker, J., Schmoll, T., Jarchau, T., Korhonen, T.K., and Goebel, W. (1986) Analysis of the genetic determinants coding for the S-fimbrial adhesin (sfa) in different Escherichia coli strains causing meningitis or urinary tract infections. Infect Immun 54: 646-653.

Pallesen, L., Madsen, O., and Klemm, P. (1989) Regulation of the phase switch controlling expression of type 1 fimbriae in Escherichia coli. Mol Microbiol 3: 925-931.
Pawelzik, M., Heeseman, J., Hacker, J., and Opferkuch, W. (1988) Cloning and characterization of a new type of fimbriae (S/F 1C-related fimbriae) expressed by an Escherichia coli 075: $\mathrm{K} 1: \mathrm{H} 7$ blood culture isolate. Infect Immun 56: 2918-2924.

Purcell, B.K., and Clegg, S. (1983) Construction and expression of a recombinant plasmid encoding type 1 fimbriae of a urinary Klebsiella pneumoniae isolate. Infect Immun 39: 1122-1127.

Singer, M., Baker, T.A., Schnitzler, G., Deischel, S.M., Goel, M., Dove, W., Jaacks, K.J., Grossman, A.D., and Gross, C.A. (1989) A collection of strains containing genetically linked alternative antibiotic resistance elements for genetic mapping of Escherichia coli. Microbiol Rev 53: 1-24. 
This document is a scanned copy of a printed document. No warranty is given about the accuracy of the copy. Users should refer to the original published version of the material. 